\title{
Chapter 6 \\ Creative Ways to Approach the Theme of Cultural Diversity in Wordless \\ Picturebooks Through Visual Reading and Thinking
}

\author{
Marina Rodosthenous-Balafa, Maria Chatzianastasi, \\ and Agni Stylianou-Georgiou
}

\subsection{Introduction}

Cultural diversity, as one of the most important characteristics of European community in the framework of the DIALLS project (see Chapter 1 for overview), is integral to notions of cultural identity and cultural literacy. The acknowledgement of identity formation as an ongoing, dynamic process through interaction rather than a preconceived characteristic arises as an imperative need, in order to encourage democracy to thrive through constructive confrontation and integration (Rapanta et al. 2020). According to Bland, picturebooks that authentically reflect cultural diversity can move even young readers towards "flexibility of perspective" $(2016,45)$. Bishop (1990) highlights the need for young readers to recognise themselves in books they read, learn about the lives of other people, and be able to cross between groups and worlds. However, reading wordless picturebooks can be a challenging task, because of the ambiguity and open nature of their visually rendered narratives. The affordances of wordless picturebooks and the challenges embedded in their reading are discussed by the authors in Chapter 5 of this volume. This chapter presents several creative ways to analyze and approach the theme of cultural diversity in class, through various disciplinary lenses and methodological approaches.

Our methodology combines elements from book and picturebook analysis drawing from the work of key theorists such as Gérard Genette, William Moebius, Emma Bosch, Perry Nodelman, Frank Serafini and Evelyn Arizpe. Specifically, it considers peritextual elements, characters and visual codes such as color, position, perspective, size, frames and line work together to represent cultural diversity. Focusing on the wordless picturebooks Naar de Markt (2017), by Noëlle Smit, and Zaterdag (2018), by Saskia Halfmouw, which reflect diversity through multiple layers

\footnotetext{
M. Rodosthenous-Balafa ( $\varangle) \cdot$ M. Chatzianastasi · A. Stylianou-Georgiou Department of Education, University of Nicosia, Nicosia, Cyprus

e-mail: rodosthenous.m@unic.ac.cy 
and ways, our analysis addresses the complexity and plurality of a picturebook and of the various readings that emerge through the different disciplinary perspectives and experiences of readers. It is useful to mention that the particular books belong to a subgenre of wordless books called 'wimmelbooks' (Rémi 2011). Such books display a series of panoramas involving richness in detail and a large number of characters. This kind of book heightens the role of readers and allows them to find their own way through their rich material as they engage in manifold reading options (Rémi 2011). In order to highlight the significance of such layered readings in a classroom setting, this chapter suggests using "thinking routines" from Project Zero (Ritchhart et al. 2011) that encourage the exploration of multiple viewpoints as a way to enrich students' understanding of cultural diversity. Our choice of such techniques suits well the affordances of picturebooks, since they allow readers to acknowledge cultural diversity, arising from the visual narrative of each book, through zoom-in or zoom-out perspectives.

\subsection{Naar de Markt}

A substantial expression of cultural diversity as well as of the richness in the heritages comprising contemporary societies can be found in Noëlle Smit's Naar de Markt [To the Market], a thirty-two-page long picturebook depicting an outdoor market, published in the Netherlands in 2017 by Querido Publishers. On every double-page spread $^{1}$ of this book, readers are invited to follow a mother and her daughter around the market and explore its multisensory experiences. Vendors promoting local goods and diverse people walking and shopping around the market represent a diverse community. Each double-page spread features a different market stall and stages the dynamic encounter and interactions between people. "The effect of this is celebratory; the book demonstrates that European identity is by definition diverse and encourages readers to consider the role of food and shopping in their own life, local community, and European community" (DIALLS 2018, 56).

The book's covers work as the starting point of this visual narrative. On the front cover, a mother and a daughter-we assume — are walking among the trees, holding a shopping basket each while their dog stares at a bird on top of a white and yellow tent in the distance. As they turn their backs to the reader, the image invites readers to follow them and make hypotheses about the content of the book. A straight diagonal line - the dog's leash-also draws attention to the dog on the lower right quadrant of the image. The image of the dog, which repeats itself in the title page, elicits hypotheses about its role in the narrative. Just like the book's characters, the role of the dog seems significant since it is involved in the multiple parallel stories taking place in the book from a diverse point of view that enhances the richness and diversity

\footnotetext{
${ }^{1}$ Double-page spread is a term referring to an illustration spreading across two facing pages (opening). In the two picturebooks discussed in this chapter all the openings are double-page spreads (see Serafini 2014, 76-77).
} 
of the market experience. On the back cover, the pair is seen riding their bikes, moving inwards to the right of the page, as if they are entering the scene. Their bikes are loaded with empty shopping baskets and the dog appears in the bicycle's basket.

The title helps to clarify the content of the two cover pictures for readers. Specifically, Naar de Markt is a thematic title, meaning that it suggests the subject matter of the book (Genette 2001). There is a direct link between the title and the content of the book. Paying attention to the title, readers can assume that the pair presented on the cover pictures might be heading towards a marketplace and this is the reason why they are carrying their shopping baskets with them. Beckett (2012) notes, "If the title is considered a paratextual element, it is certainly the most important one and the most intimately linked to the text itself" (117). Exploring the title can prepare readers for the market they are about to see. It orientates and contextualises the reading, providing readers with clues in order to interpret both the visual signs of covers, as well as those inside the book (Bosch 2014). Although it can answer some of the potential hypotheses inspired by the images regarding where mother and daughter are heading, this brief title also creates some space for readers to make their own interpretations (see the discussion in Chapter 5).

Opening the book, a bird's eye view of a number of colorful umbrellas features on the endpapers. The endpapers- "elements of the overall format and design of the book" - are deliberately chosen to suit the mood and tone of the book and can be essential in the storytelling process (Gamble 2013, 210). Here, the choice of this endpaper illustration has both literal and metaphorical connotations, as a coded marker of diversity. Recognizing signs like this is essential in reading what this visually rich book has to offer, especially because "picturebooks are artefacts that convey cultural ideas to help readers learn about their world" (Koss 2015, 32). Moving from what is noticed in the visual images towards its meaning is therefore an important aspect of the comprehension process (Serafini 2011). Important elements to be considered here in how they convey meaning are borders, line, and color. In the book, the absence of borders allows the illustrations to bleed into the edges of the page. The absence of borders can offer a more holistic reading experience, allowing readers to connect with the artistic elements of illustration and see things from within. Because of the richness of the visual experience offered by the illustrations of Naar de Markt, it is very important that the reader pauses and slows down in order to connect and engage with visual codes to make sense of both the artistic elements and the cultural connotations these have to offer. Lines, which define the objects on the page, are evidently absent, drawing readers attention to the use of color. Color can be considered "one of the most emotionally evocative artistic elements", meaning that it particularly suitable for suggesting symbolic associations (Giorgis et al. 1999, 148; Gamble 2013). The wide range of colors used in this vibrant depiction of the market can help readers to recognize cultural diversity, through differences in the color or clothes, objects, or even skin and hair showing that diversity is everywhere.

These elements can be recognized in the first double-page spread of the book, which opens the story with a panoramic bird's eye view revealing the market, as well as in the next pages. The tents and umbrellas spread out under the trees between two lines of buildings. The focal point of the page is the market in the center of 
the picture, with people coming and going. On the lower right corner of the page, the mother and daughter are seen with their dog. The two function as a guide for readers to follow throughout the pages. Their white clothes let them stand out and be spotted easily in the otherwise full of color setting; the neutral white color creates an antithesis of the other bold colors used in each page.

Following the two protagonists, readers get the opportunity to visit first a Dutch fish market and a stall with seafood delicacies. Next is a butchers' stall with different types of sausages, and large pieces of meat hanging from the top, as well as a rich variety of meats. The shopping continues to a fruit market stall, with green and white patterns on its tent. There is also a cheese market stall, a market table with olives and other delicacies, a bakery stall, a book seller, a seller of dresses and hats, a flower market, and a corner stall with second-hand items. As mother and daughter continue their shopping from one stall to another, readers get the opportunity to explore the various cultural markers hidden in the illustration such as the color patterns possibly pointing to the flags of specific countries, the traditional costumes or products traditionally linked to specific cultures and heritages. The variety of goods and food sold in this market as well as the cultural markers that some readers can identify on the pages of the books point towards the richness of diversity in the heritages at the roots of many European societies. Crucially, however, reading this book in the class needs to be done with a sense of caution to avoid stereotyping diversity and reproducing a representation of cultures that can challenge the acceptance and celebration of such diversity.

While the shopping continues, diversity is also revealed as parallel stories and incidents unfold. A cat leaves its owner and steals smoked anchovies from a vendor, who angrily follows the cat. An old lady turns to look at what is happening, while another lady, who is later seen living with her cat in an apartment with a balcony above the market, keeps walking indifferently. The young girl stops to help a lady collect the oranges that have fallen on the ground, and leaves her basket behind, while she later tries some cheese with her mother. When she finally realizes she lost her basket, a man, who found it, approaches the girl to return it. People of different ages, gender, backgrounds, origins, national and cultural identities, color, and status equally coexist in this colorful and rich celebration of diversity and cultural heritages. Vendors and customers with traditional clothes or garments, people from next door with different personalities and styles, as well as people from minority groups, all have an active role in this book. They mix and mingle, communicate, and interact with each other, transforming the market into a place of social and cultural encounters and intercultural exchanges, visually helping readers to experience cultural diversity. This attests to Bland's argument that, by demonstrating the commonality of human experience and opening a space for the exploration of cultural identities and the ability to change perspective, picturebooks can potentially contribute to the acquisition of intercultural competence (2016). Each character in this visual narrative carries his/her own story, but at the same time, each is offered the opportunity to negotiate his/her identity and be influenced by others.

This identity formation in relation to others' cultural identity is finally celebrated in the last double-page spread of the book in which the mother prepares a party 
table with all the goods and food she bought. All the different heritages are evident through the items on the table. Previously dressed in white, the mother and daughter now wear the dresses they bought from the market; the change from neutral white may symbolically reflect the continuous process of one's construction of cultural identity in relation to the identities of others. Mother and daughter work as examples of an "individual's disposition and competence to encounter cultural differences and to elaborate one's own identity in respectful social interaction with other people", which is integral in the DIALLS' reconceptualization of cultural literacy (Maine et al. 2019, 387). This competence can also be recognized in the multiplicity of recurring characters, appearing in Zaterdag, the second Dutch wordless picturebook that is discussed next.

\subsection{Zaterdag}

Zaterdag is a wordless picturebook by Saskia Halfmouw published by Leopold Editions in Amsterdam in 2018. It is a book about various activities people selectively do throughout the year "on the best day of the week"; that is Saturday, which is also the translation of the book's title in English. The picturebook is a series of twelve facing pages (openings), representing one setting at a time and various characters who do different activities within that setting. Number twelve also echoes the twelve months of the year, showing how, in particular, countries' activities on Saturdays could vary from season to season.

Starting from the first opening, readers face several football fields, where mixed teams of children play; the second one is a central square, with open food markets, restaurants, and apartment buildings; the third one is a supermarket; an indoor swimming pool follows, then a library, a beach, several neighborhood playgrounds, a forest, an open market with a variety of goods, a dinosaur museum, a ski resort, and finally a Christmas decorated piazza. All illustrations of settings have a panoramic perspective, and they are unframed, "constituting", according to Moebius (1986), "a total experience, the view from "within"” (50).

Before exploring the cultural dimensions of the content and the characters of the book, the reader might find it useful to focus on its peritextual elements (Genette 1997) such as the note on the back cover, the note by the illustrator or the publisher at the left-hand side (verso) of the title page, and the notes on the final endpapers of the picturebook. All these brief verbal texts provide clues about the content of the specific wordless book and help the reader decode certain dimensions of the visual narrative, since it has multiple meanings and perspectives.

The note on the back cover is in red typeface and functions as an alternative "summary" of the wordless picturebook to help readers decide whether the picturebook is interesting to them:

Finally. It's Saturday. No school. What do you do on the best day of the week? Playing football, swimming, going to the supermarket or on an adventure in the dinosaur museum... 
Wander through this large viewing and search the book, which is full of Saturday fun. Can you find everyone?

Another note (in smaller, black characters) is added below, introducing the illustrator, who is well-known in her country for illustrating a famous book character by Paul van Loon called Foeksia, who is a little witch in a purple hat.

Although the above final note refers to the variety of activities in which the book's characters engage every Saturday, the initial note inside the book concentrates on the variety of the main characters themselves:

Can you find everyone? Find the cowboy boy, the escaped dog, the boy with the ball, famous book characters, and many more children, dads, moms, grandfathers and grandmothers. Can you also recognize a fairy tale figure on every opening?

You will find the solution on the endpaper in the back.

Both notes include the question "Can you find everyone?", which makes the whole procedure of reading the visual narrative a game. Bosch points out: "Some wordless and almost wordless picturebooks include games to encourage re-reading. These games are complementary given that, if the game were the essence of the book, it would be a game book" $(2014,86)$. This specific note reveals two important hints: (a) fairy tale figures to be found in each opening; and (b) guidelines that are provided at the back endpage of the picturebook. The reader, looking at the final endpapers, observes the same exact depictions of characters that are found on the initial endpapers, with an extra addition of a note at the back verso endpage, mentioning the setting of each opening, followed by a name of a fairy tale figure. In this way, the reader realizes that the particular figures appear in certain settings, waiting to be found, and turning reading playfully multidimensional, since the reader needs to follow the story of several realistic characters as they mingle with various fictional ones.

At this point, a reader might be prompted to consider how many kinds of characters appear in Zaterdag and what their possible interconnections are. This question helps readers understand how culture is illustrated in this picturebook and how cultural diversity encourages a peaceful and respectful environment. Therefore, our analysis focuses on a detailed description of the different type-characters appearing in the book.

As is shown on the endpapers of the picturebook, the characters of Zaterdag include a variety of dogs and realistic persons of everyday life. Although the majority of characters are young children, there are characters of all ages (babies, young people, middle-aged and third-aged people). In this way, not only does Zaterdag depict children's activities in each setting but it presents the activities of all ages. These realistic characters, who appeared on the endpapers, are recurrent in every double-page spread, where a particular setting is presented. They are kind of "stock" characters who have distinct characteristics or duties, and the reader can easily spot them in each opening. In particular, there is an elegant seventy-year-old lady accompanied by a small dog; a middle-aged man; a young woman in a style like that of a mermaid (green hair, a fish-shaped bag, and a mermaid swimsuit when it is applicable); children who are in groups or stand alone, playing with their favorite toys, 
gadgets, or sports equipment (balls, mobiles, ski equipment); a young cowboy who has several responsibilities and carries out tasks (delivers balls to the football fields, potatoes to the market, frozen pizzas to the supermarket, ice-creams at the beach, snowballs at the ski resort, etc.); babies in buggies; children who pretend to play roles, such as pirates and donut sellers; a girl in a wheelchair or a sleigh, according to where she is. Usually, children are accompanied by their mothers or fathers, or their friends who are the same age. A total of thirty-three characters appear on the endpapers. Nuclear families are rare. ${ }^{2}$ Dogs, unlike cats, have protagonistic roles. Seven dogs appear as stock characters on the endpapers and they usually accompany children.

Apart from these repetitive characters, there are many more everyday, secondary characters in each opening. For example, coaches appear at the football fields, whereas outside the fields, two old men are walking and chatting. There are different dogs in each opening, various sellers in the markets, people of different nationalities, grandparents of the stock characters, beggars, and homeless people. At the museum, a punk is taking a selfie in front of a dinosaur, the famous Dutch children's writer Paul van Loon can be spotted in the library, and there is a huge diversity of other people experiencing Saturday activities in the book, as in real life.

The third category of characters are fictional ones, particularly the twelve fairy tale figures mentioned on the final endpaper. These are Tom Thumb, Rapunzel, Pinocchio, the Frog Prince, Puss in Boots, Aladdin and the Wonderful Lamp, the Girl in the Red Shoes, Little Red Riding Hood, Sleeping Beauty, Cinderella, Snow White, and the Little Match Girl. Interestingly, these figures are related to the depicted background in either a more symbolic or clearer way. For example, Snow White, as her name denotes, appears at the ski resort, and the heroine in Hans Christian Andersen's story, The Little Match Girl, appears in the Christmas opening, sitting alone outside a shop, holding a lit match, since Andersen's story takes place on a freezing New Year's Eve. Little Red Riding Hood appears with her basket in the forest where the Big Bad Wolf lurks in the trees. Aladdin is spotted sitting on his magic carpet at the beach, which is like the beach mats the other swimmers use. In an ironic way, the sneaky Puss in Boots is on the library's staircase reading a book as a witty man. The blending of different realistic characters with completely dissimilar fairy tale characters, who represent certain positive or negative attitudes of human beings, shows in a metaphoric, fascinating, and playful way that diversity is part of life and culture.

The fourth category of characters includes famous book characters, who appear in the settings, particularly in the library, where they come to life from the books. There, the reader can spot Harry Potter dressed in a robe and holding his magic wand. Foeksia, the little witch, is hiding behind the sofa and there is also Dolfje the Werewolf, who are both characters from Paul van Loon's stories and illustrated by Saskia Halfmouw (Van Loon 2014). More book characters can be spotted by a well-informed reader, who can see the intertextual game of the illustrator.

\footnotetext{
${ }^{2}$ There is a hint on the endpapers of a same gender parent family, but it is not clear throughout the book whether this is a nuclear family or two single parents, getting along with each other.
} 
The fifth category of characters that take part are those drawn by children, and they "revive" while watching the kids playing. Between the paintings and real life, there is often confusion, and this is illustrated by a realistic dog that wants to get acquainted with a painted dog (see the opening of the neighborhood playgrounds). These imaginary characters can be found in the museum, where a girl is drawing a dinosaur on a floor; in the snow at the ski resort; on the street in the open market; and in the sand at the beach.

It is without a doubt that Zaterdag is a picturebook with many intertextual connotations in relation to Saturday activities of realistic, fictional, and imaginary characters. In this way, the cultural diversity element appears at multiple levels, first, through the appearance of folk characters and characters of eponymous literary history, and their interaction with realistic characters. The fictional characters, just like the realistic ones, come from different cultures and narratives, and share different mentalities and ways of living. Despite all that, their coexistence in the setting is harmonious and fully acceptable. The second aspect of cultural diversity in this picturebook is relevant to social interaction (either direct or indirect) and acceptance of the other, who is of different nationality, gender, age, style, abilities, needs, or tastes. All people live together in the same community, in different but peaceful and respectful ways. All twelve openings of this picturebook do not simply show the variety of activities one can do on the best day of the week but they comprise a significant tool to approach cultural diversity in and outside the class.

\subsection{Creative Practices of Approaching Cultural Identity Wordless Picturebooks}

Our analysis of Naar de Markt and Zaterdag has shown that picturebooks' visual richness offers various paths of interpretation - a point also made in Chapter 5-that may give rise to students' multiple points of view and encourage the expression of diverse ideas. Arizpe suggests that classroom practices involving wordless picturebooks do not take into account their "particular nature" and the "heightened role of the reader" $(2013,164)$. There is to date no systematic study of what Nodelman (1988, 191) refers to as the "communicative powers of visual codes" in wordless books.

The following approaches consider the two wordless books examined above as points of reference to start a visual reading journey towards a creative play of perspective-taking to unfold multi-layered meanings. We consider learning to read a wordless picturebook as an enculturation process (Brown et al. 1989). Participating in meaningful activities, readers can learn how to use thinking dispositions (Tishman et al. 1993) as tools to understand the "silent language of images" (Tan 2011, cited in Arizpe 2013, 174). Therefore, they are adopting the practice but also the set of beliefs and idiosyncrasies of the community in and out of a wordless book. Approaching wordlessness requires skillful facilitators of close reading who 
are willing to take the "beautiful risk" of welcoming uncertainty in the classroom (Beghetto 2017, 24), tolerating ambiguity, and communicating to readers that not everything may be answered or understood (Arizpe 2014). Readers should experience the polyphonic creative process of teaching which evolves "not in a single line of action or thought, but in several strands and directions at once, enabling the risk to be borne or not" (Burnard 2011, 58).

\subsection{Using a Thinking Palette Metaphor as a Toolbox to Read Wordless Books}

Using an artist's palette as a metaphor, where colors represent tools for participating in a creative process, readers can engage in visual reading by picking up the colors to create meaning. The "Artful Thinking Palette" framework has been introduced and used in the Artful Thinking Project by Project Zero at the Harvard Graduate School of Education (Tishman and Palmer 2006). According to this framework, students are encouraged to use six thinking dispositions each represented by a different color (Red: Reasoning; Blue: Questioning \& Investigating; Yellow: Exploring Viewpoints; Green: Observing \& Describing; Orange: Comparing \& Connecting; Purple: Finding Complexity). The objective is to make thinking visible by strengthening forms of intellectual behaviors as an enculturation process (Tishman et al. 1993). Each thinking disposition has several "thinking routines" (Ritchhart et al. 2011, 43) which can be used flexibly to deepen students' thinking not only with visual art but with diverse topics in the school curriculum. This framework has been used in grades $\mathrm{K}-12$ as well as in post-secondary education. We propose that the six thinking dispositions could be useful tools for guiding the reading of wordless picturebooks. In this chapter, we chose to focus on the yellow color, which involves thinking routines functioning as a zoom-in perspective to imagine things differently as well as routines for zooming-out to explore diverse perspectives.

\subsubsection{Exploring Viewpoints While Reading: Diversity Through a Zoom-In Perspective}

\subsubsection{Thinking Routine "Stories"}

The "Stories" thinking routine (Project Zero's Thinking Routine Toolbox, n.d.) aims to encourage rethinking the various angles of complex issues. Learners are prompted to answer three questions: "What is the story that is presented?", "What is the untold story?", and "What is your story?".

What is the story? In both wordless books, there are many stories presented. Zaterdag: the inhabitants of the town spend their Saturday doing diverse activities. 
Naar de Markt: a mother and daughter visit an open market. Each character carries his/her/its own story.

What is the untold story? Readers are invited to observe what has been emphasized in the visuals of the two wordless picturebooks and what has been made less significant. For example, an untold story in both books is the complex issue of cultural diversity in many forms (gender, personality, objects, etc.). Educators can use questions such as: What might the characters not want us to know about? What do the characters not pay attention to or don't think about? How/Why do characters find themselves in specific settings? For example, How do fairy tale characters relate to the specific setting they appear in? (see Zatertag), or How and why do vendors with various cultural heritages end up selling their products in that particular market in a Dutch town? (see Naar de Markt).

What is your story? Readers are invited to bring their own perspective to the issue of cultural diversity and ask themselves: What would you do on a Saturday or what would you do at an open market? How would you rewrite the story if you were a main character? How would this story be like in your local context? How would you represent yourself in the book? How would this representation be similar/different from the existing characters?

Applying this thinking routine, reading zooms into the stories of the main characters, considering three different perspectives (told story, untold story, your own story) encouraging an intercultural understanding of diversity. Readers can think how visual symbols are used to present identity and cultural heritage in a Dutch context (i.e. of vendors and customers in Naar de Markt or inhabitants of a town in Zaterdag).

\subsubsection{Thinking Routine "Pass the Parcel"}

The "Pass the Parcel" thinking routine (Project Zero's Thinking Routine Toolbox, n.d.) is another way to encourage a zoom-in perspective through play. The wellknown children's party game is used as a metaphor to foster deep learning and understanding. The layers are removed as learning and understanding deepen. With each layer unwrapped, students get closer to the prize: core knowledge, understanding. We claim that such a routine can be used with wordless picture books to provoke curiosity and introduce reading as a playful, dynamic, and interactive process. Teachers can invite students or groups to suggest what they would like to explore in a wordless picturebook. A list of key points discovered in their visual journey is created and wrapped up as a "treasure". Students continue wrapping up this treasure, placing on each layer a question that they had been asking themselves. Then, they invite other classmates in to play the game. In this way individuals or small groups could share views seen through different perspectives. For younger readers, the teacher can scaffold the process by posing students' questions for each layer.

Using this thinking routine when reading Zaterdag and Naar de Markt, readers can be prompted to choose any aspect of the book they would like to explore (i.e., characters, peoples' clothes, animal behavior, flags, products) and think how they are related to cultural diversity. For example, readers can choose a character and focus 
on visual symbols as expressions of their identity and how they interact with others in a multicultural context (e.g., Zaterdag: the girl on the wheelchair, or Naar de Markt: the party table with goods from various places). The treasure in this case could be a main idea arising from the books, like "diversity is everywhere." Questions for the visual journey could be: How are certain objects part of our identity? How do people coexist in a locale? Such questioning requires skillful facilitation of group or wholeclass discussion so as not to lead children to stereotyping (i.e. make judgements or assumptions about people based on their visual representations).

\subsubsection{Exploring Viewpoints While Reading: Diversity Through a Zoom-Out Perspective}

\subsubsection{Thinking Routine "Projecting Across Distance"}

"Projecting Across Distance" thinking routine (Project Zero's Thinking Routine Toolbox, n.d.) encourages a broader, multi-perspective view of a topic, since students are invited to consider how it is viewed in (a) their community; (b) another city or town in their country; and (c) other countries. Therefore, they can compare and discuss what might be the reason behind the similarities and/or differences between and within the communities and countries. A zoom-out perspective when reading the book Naar de Markt allows readers to consider the role of food and shopping in their own life, the role of the market in their community and other contexts (countries), and how the marketplace is at the root of social European and other identities. Readers can be prompted to answer questions such as: Does an open market in my local community look like a market in The Netherlands/Europe/other countries in the world and why?

Projecting across distance while reading Zaterdag, children open up their thinking and look at cultural diversity in their own locale, considering the inhabitants of their own community and the activities they engage in on a Saturday. Questions like: What are the activities that people in your community/country/other countries do on a Saturday? Which fictional characters would appear from your literary local tradition/your country's tradition/neighboring country's tradition? As readers adopt a zoom-out perspective, they might consider and appreciate diverse social and cultural contexts, other than the ones appearing in Zaterdag. For example, in Israel Saturday is not reflected in Zaterdag's pages, since Jewish children would not be out playing on Sabbath.

Readers can benefit from close reading of the visual narrative of the two wordless picturebooks by adopting zoom-in or zoom-out perspectives that provide insight into cultural diversity. However, we acknowledge that teaching diversity to young children is a challenging and complex task. It requires skillful educators who guide visual reading journeys using tools that centralize critical thinking, thus making it visible to others and open to dialogue. In this way stereotypical assumptions can 
be challenged. The two wordless picturebooks should be used as springboards for celebrating difference, without reinforcing notions of "others" being different but rather reinforcing "we" are all different.

\subsection{Conclusion}

The two picturebooks are a clear reflection of how modern societies are characterized by plurality of cultures and heritages, as well as divergent, even competing, narratives and notions of cultural artifacts and traditions. The individual's identitybuilding process thus always occurs in relation to surrounding "super-diversity" (see the discussion in Chapter 4) and social interaction with other people. This interconnection between people's lives is key for constructing one's own cultural identity as well as for encountering other people and facing cultural differences (Maine et al. 2019, 386). As this chapter has shown, the close-reading of such books can offer a number of critical and creative ways of analyzing and understanding how visual narratives potentially help readers acknowledge and understand cultural diversity. Moreover, the chapter has suggested several thinking strategies that can contribute to the systematic implementation of various ways to consider multiple viewpoints in the classroom. Our methodology offers ideas for empirical implementation in future studies that can show how this approach can offer pathways for young readers to experience, accept, and celebrate early on their lives' cultural diversity. This can be an advantage for future citizens and the societies of the twenty-first century.

\section{References}

Arizpe, E. 2013. Meaning-making from wordless (or nearly wordless) picturebooks: What educational research expects and what readers have to say. Cambridge Journal of Education 43 (2): $163-176$.

Arizpe, E. 2014. Wordless picturebooks: Critical and educational perspectives on meaning making. In Picturebooks: Representation and narration, ed. Bettina Kümmerling-Meibauer, 91-106. New York, NY: Routledge.

Beckett, S.L. 2012. Crossover picturebooks: A genre for all ages. London: Routledge.

Beghetto, R.A. 2017. Inviting uncertainty into the classroom: Five strategies to help students respond well to uncertainty and foster complex problem-solving skills. Educational Leadership 75 (2): 20-25.

Bishop, R.S. 1990. Mirrors, windows, and sliding glass doors. Perspectives: Choosing and Using Books for the Classroom 6 (3): ix-xi. https://www.psdschools.org/webfm/8559.

Bland, J. 2016. English language education and ideological issues: Picturebooks and diversity. CLELE Journal 4 (2): 41-64.

Bosch, E. 2014. Texts and peritexts in wordless and almost wordless picturebooks. In Picturebooks: Representation and narration, ed. Bettina Kümmerling-Meibauer, 71-90. New York: Routledge.

Brown, J.S., A. Collins, and P. Duguid. 1989. Situated cognition and the culture of learning. Educational Researcher 18 (1): 32-42. 
Burnard, P. 2011. Creativity, pedagogic partnerships, and the improvisatory space of teaching. In Structure and improvisation in creative teaching, ed. R. Keith Sawyer, 51-72. New York: Cambridge University.

DIALLS (DIalogue and Argumentation for Cultural Literacy Learning in Schools). 2018. Bibliography of cultural texts. https://dialls2020.eu/wp-content/uploads/2019/09/Bibliography-of-Cul tural-Texts.pdf. Accessed 27 June 2020.

Gamble, N. 2013. Exploring children's literature. Reading with pleasure and purpose. London: Sage.

Genette, G. 1997. Thresholds of interpretation, trans. J.E. Lewin. Cambridge: Cambridge University Press.

Genette, G. 2001. Umbrales. Mexico, DF and Buenos Aires: Siglo XX1.

Giorgis, C., N.J. Johnson, A. Bonomo, C. Colbert, A. Conner, Gloria Kauffman, and Dottie Kulesza. 1999. Children's books: Visual literacy. The Reading Teacher 53 (2): 146-153.

Halfmouw, S. 2018. Zaterdag. Amsterdam: Leopold.

Koss, M.D. 2015. Diversity in contemporary picturebooks: A content analysis. Journal of Children's Literature 41 (1): 32-42.

Maine, F., V. Cook, and T. Lähdesmäki. 2019. Reconceptualizing cultural literacy as a dialogic practice. London Review of Education 17 (3): 383-392. https://doi.org/10.18546/LRE.17.3.12.

Moebius, W. 1986. Introduction to picturebook codes. Word and Image: A Journal of Verbal/Visual Enquiry 2: 141-158. https://doi.org/10.1080/02666286.1986.10435598.

Nodelman, P. 1988. Words about pictures: The narrative art of children's picture books. Athens, GA: University of Georgia Press.

Project Zero's Thinking Routine Toolbox. n.d. Retrieved from Project Zero of Harvard Graduate School of Education website: https://www.pz.harvard.edu/thinking-routines. Accessed 1 September 2020.

Rapanta, C., M. Vrikki, and M. Evagorou. 2020. Preparing culturally literate citizens through dialogue and argumentation: rethinking citizenship education. The Curriculum Journal. https:// doi.org/10.1002/curj.95. Accessed 17 January 2020.

Rémi, C. 2011. Reading as playing. The cognitive challenge of the wimmelbook. Studies in Language and Literacy 13: 115-140.

Ritchhart, R., M. Church, and K. Morrison. 2011. Making thinking visible: How to promote engagement, understanding, and independence for all learners. San Francisco, CA: Jossey-Bass.

Serafini, F. 2011. Expanding perspectives for comprehending visual images in multimodal texts. Journal of Adolescent \& Adult Literacy 54 (5): 342-350.

Serafini, F. 2014. Reading the visual: An introduction to teaching multimodal literacy. New York: Teachers College Press.

Smit, N. 2017. Naar de Markt. Amsterdam: Querido.

Tishman, S., E. Jay, and D.N. Perkins. 1993. Thinking dispositions: From transmission to enculturation. Theory into Practice 32 (3): 147-153.

Tishman, S., and P. Palmer. 2006. Artful thinking: Stronger thinking and learning through the power of art (Final Report). Cambridge, MA: Project Zero, Harvard Graduate School of Education, November.

Van Loon, P. 2014. Een miniheks in het Weerwolvenbos, illust. S. Halfmouw and H. van Look. Amsterdam: Leopold.

Marina Rodosthenous-Balafa is an Associate Professor in Modern Greek Literature in the Education Department at University of Nicosia. She is the coordinator of the MA Programme: Teaching of Language and Literature (MEd).

Maria Chatzianastasi is a Postdoctoral Researcher at the University of Nicosia. Her research interests focus on the aesthetic and pedagogic aspects of children's literature, children's literature in education, contemporary trends and controversial themes in children's books. 
Agni Stylianou-Georgiou is an Associate Professor of Educational Psychology at the University of Nicosia. Her current research is in the area of metacognition, creative curriculum design, and problem-solving.

Open Access This chapter is licensed under the terms of the Creative Commons Attribution 4.0 International License (http://creativecommons.org/licenses/by/4.0/), which permits use, sharing, adaptation, distribution and reproduction in any medium or format, as long as you give appropriate credit to the original author(s) and the source, provide a link to the Creative Commons license and indicate if changes were made.

The images or other third party material in this chapter are included in the chapter's Creative Commons license, unless indicated otherwise in a credit line to the material. If material is not included in the chapter's Creative Commons license and your intended use is not permitted by statutory regulation or exceeds the permitted use, you will need to obtain permission directly from the copyright holder.

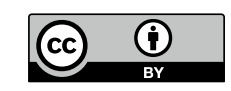

